\title{
Interaction between staining and degradation of a composite resin in contact with colored foods
}

\begin{abstract}
Debora Soares-Geraldo(a) Taís Scaramucci(a)

Washington Steagall-Jr(a)

Sheila Regina Maia Braga(a)

Maria Angela Pita Sobral(a)
\end{abstract}

(a) Department of Restorative Dentistry, School of Dentistry, University of São Paulo, São Paulo, Brazil.
Declaration of Interests: The authors certify that they have no commercial or associative interest that represents a conflict of interest in connection with the manuscript.

Corresponding author: Maria Angela Pita Sobral E-mail: mapsobra@usp.br

Received for publication on May 18, 2011 Accepted for publication on Jul 13, 2011

\begin{abstract}
Composite resins might be susceptible to degradation and staining when in contact with some foods and drinks. This study evaluated color alteration and changes in microhardness of a microhybrid composite after immersion in different colored foods and determined whether there was a correlation between these two variables. Eighty composite disks were randomly divided into 8 experimental groups $(\mathrm{n}=10)$ : kept dry; deionized water; orange juice; passion fruit juice; grape juice; ketchup; mustard and soy sauce. The disks were individually immersed in their respective test substance at $37^{\circ} \mathrm{C}$, for a period of 28 days. Superficial analysis of the disk specimens was performed by taking microhardness measurements (Vickers, $50 \mathrm{~g}$ load for 45 seconds) and color alterations were determined with a spectrophotometer (CINTRA 10- using a CIEL*a*b* system, 400-700 nm wavelength, illuminant $\mathrm{d} 65$ and standard observer of $2^{\circ}$ ) at the following times: baseline (before immersion), 1, 7, 14, 21 and 28 days. Results were analyzed by ANOVA and Tukey's test $(\mathrm{p}<0.05)$. Both variables were also submitted to Pearson's correlation test $(\mathrm{p}<0.05)$. The passion fruit group underwent the greatest microhardness change, while the mustard group suffered the greatest color alteration. Significant positive correlation was found between the two variables for the groups deionized water, grape juice, soy sauce and ketchup. Not all color alteration could be associated with surface degradation.
\end{abstract}

Descriptors: Composite Resins; Coloring Agents; Hardness; Dental Restoration Failure.

\section{Introduction}

In the era of the tooth-colored dental restorations, color stability has become one of the major requirements of restorative materials. It is well known that the original color of composite resins can be changed within a certain period of time. ${ }^{1}$ The long-term color changes in composite restorations can occur due to surface and marginal staining, microleakage, wear-dependent surface changes, and internal material deterioration, which may compromise the visual acceptability of these restorations and result in additional expenses for replacement. ${ }^{2}$ Secondary caries was the main reason for failure of resin composite, followed by discoloration. ${ }^{3}$ This process concerns patient and dentist and consumes time and money. ${ }^{4}$

Surface staining of a composite is mainly related to the absorption or 
adsorption of coloring substances, ${ }^{4-7}$ such as those found in the patient's diet. In modern societies diet includes a wide range of colored foods and drinks, which can affect the natural color of composite restorations to different degrees. So far, many studies have extensively reported the harmful effects of coffee, tea, grape juice, yerba mate and cola drinks on dental composites. ${ }^{8-10}$ More recently, other reseachers ${ }^{4,11-13}$ reported the color changes promoted by lemon juice, cherry juice, carrot juice, red wine, snow cone syrup and grape drink. However, there are some other important colored foods that are very common in the patient's diet, such as ketchup and mustard, and yet, the effects of these foods on the color of composites have received little attention. Fontes et al. ${ }^{10}$ advised additional studies to investigate the color stability of composite resin-based materials.

In addition to color alteration, some of these products can also cause superficial degradation on the composite surface by reducing its microhardness, ${ }^{14}$ which could possibly favor more superficial staining. Corroborating this theory, Okte et al. ${ }^{15}$ showed decreased microhardness values of microhybrid and nano resin composites after immersion in both, coffee and wine solutions. Therefore, the aim of this study was to evaluate the color and microhardness alterations of a composite resin when immersed in different colored foods and to determine whether there is a correlation between these two variables.

\section{Methodology}

\section{Disk specimens preparation}

Eighty cylindrical disk specimens of a microhy- brid composite resin (Filtek Z-250, shade A1, 3M, St. Paul, USA) were prepared using a brass mold. Forty of these disk specimens were $10 \mathrm{~mm}$ in diameter and $1.5 \mathrm{~mm}$ high (color assessment), and forty were $5 \mathrm{~mm}$ in diameter and $2 \mathrm{~mm}$ high (microhardness evaluation). Composite was dispensed, manipulated, and polymerized according to the manufacturers' instructions. The mold was placed on a transparent polyester film strip (3M Flip-Frame, 3M Visual Systems Division, Austin, USA) and a glass microscope slide. The composite was packed into the mold until it was intentionally overfilled. The material was covered with another polyester film strip and a glass microscope slide. The excess material was extruded by light pressure, and the resin composite was light polymerized with a halogen light unit (Astralis 3, Ivoclar-Vivadent, Schaan, Liechtenstein) with the light tip $1 \mathrm{~mm}$ away from the specimens. The energy density used was $500 \mathrm{~mW} /$ $\mathrm{cm}^{2}$ measured with a radiometer.

\section{Experimental procedures}

The disk specimens were randomly divided into 8 experimental groups $(n=10$, in which 5 were $10 \mathrm{~mm}$ in diameter and 5 were $5 \mathrm{~mm}$ in diameter) as described in Table 1. Each disk specimen was individually immersed in $25 \mathrm{ml}$ of its respective solution at $37^{\circ} \mathrm{C}$ for a total of 28 days. With the exception of the dry group, the solutions were replaced every 7 days. Before each evaluation, the disk specimens were washed with distilled water, gently brushed and blot dried with absorbent paper. The juices were diluted according to the manufacturers' instructions.

Table 1 - Experimental groups, products, manufacturers and $\mathrm{pH}$.

\begin{tabular}{c|c|c|c}
\hline Group Code & Products & Manufacturer & $\mathrm{pH}$ \\
\hline DRY & - & - & - \\
\hline DW & Deionized water & - & 6.3 \\
\hline ORA & Orange juice & TANG - Kraft Foods, Curitiba, Brazil & 3.01 \\
\hline PAS & Passion fruit juice & TANG - Kraft Foods, Curitiba, Brazil & 3.13 \\
\hline GRA & Grape juice & TANG - Kraft Foods, Curitiba, Brazil & 2.98 \\
\hline KET & Ketchup & Hellmans - Unilever, Goiania, Brazil & 3.66 \\
\hline MUS & Mustard & Hellmans - Unilever, Goiania, Brazil & 3.33 \\
\hline SOY & Soy sauce & Sakura NaKaya, Boituva, Brazil & 4.8 \\
\hline
\end{tabular}




\section{Color assessment}

Quantitative color measurements were performed in the $10 \mathrm{~mm}$ diameter disk specimens with the use of an ultraviolet-visible recording spectrophotometer (Cintra 10UV- Visible Spectrometer, GBC Scientific Equipment, Dandenong, Australia) according to the CIELAB (Commission Internationale de I'Eclairage $\left.L^{*}, a^{*}, b^{*}\right)$ system. The illumination source was provided by a light with 400-700 $\mathrm{nm}$ of wavelength, standard illuminant D65, standard observer of $2^{\circ}$, against a white background. The measurements were made at the following times: baseline (after the polymerization); after 1 day of immersion in the solutions (T1); after 7 (T2); 14 (T3); 21 (T4) and 28 (T5) days. Each specimen was measured twice by the same person and the $\Delta E$ values were calculated according to the formula.

$$
\Delta E=\sqrt{\Delta L^{2}+\Delta a^{2}+\Delta b^{2}}
$$

where:

$$
\begin{aligned}
& \Delta L=L_{\mathrm{Tx}}-L_{\text {Tbaseline }} \\
& \Delta a=a_{\mathrm{Tx}}-a_{\text {Tbaseline }} \\
& \Delta b=b_{\mathrm{Tx}}-b_{\text {Tbaseline }} \\
& \mathrm{Tx}=\mathrm{T} 1, \mathrm{~T} 2, \mathrm{~T} 3, \mathrm{~T} 4, \mathrm{~T} 5
\end{aligned}
$$

It is known that under clinical conditions, the human eye can detect $\Delta E$ alterations with values above 3.3. ${ }^{16}$ Therefore, qualitatively, $\Delta E>3.3$ can be considered unacceptable, and $\Delta E<3.3$ imperceptible to the normal observer.

\section{Microhardness evaluation}

Vickers surface microhardness (HMV 2000, Shimadzu, Kyoto, Japan) was determined by performing 5 indentations with $50 \mathrm{~g}$ load for 45 seconds (100 $\mu \mathrm{m}$ of distance), at the following times: after polymerization of the specimens (baseline), after 24hs (T1), 7 (T2), 14 (T3), 21 (T4) and 28 days (T5) of immersion in the solutions, where $\Delta V$ (delta Vickers) represents the difference between the initial microhardness and the measurements made after each experimental time.

\section{Statistical analysis}

Data were submitted to statistical analysis using the SPSS (Statistical Package for the Social Sciences - SPSS Inc., Chicago, USA). The data obtained were submitted to 2-way ANOVA (experimental time $\times$ staining solutions), and Tukey's tests were carried out for statistical comparisons and statistical significance $(p<0.05)$. To establish a possible relationship between staining and microhardness changes, Pearson's correlation test was used to compare the $\Delta E$ and $\Delta V$ values for each solution in all the experimental times of evaluation $(p<0.05)$.

\section{Results Color change}

Means, standard deviations $( \pm)$ and statistical difference of color changes $(\Delta E)$ for the tested substances at each experimental time are shown in Table 2. During all experimental times the groups

Table 2 - Means and standard deviations of $\Delta E$ values for each experimental time.

\begin{tabular}{c|c|c|c|c|c}
\hline Groups & T1 & T2 & T3 & T4 & T5 \\
\hline DRY & $0.56 \pm 0.10^{a, A}$ & $0.70 \pm 0.09^{a, A}$ & $0.72 \pm 0.08^{a, A}$ & $0.80 \pm 0.18^{a, A}$ & $0.88 \pm 0.51^{a, A}$ \\
\hline DW & $0.78 \pm 0.16^{a, A}$ & $1.38 \pm 0.31^{a b, B}$ & $3.41 \pm 0.42^{b, C}$ & $1.73 \pm 0.38^{a b, B}$ & $1.50 \pm 0.31^{a b, B}$ \\
\hline ORA & $0.69 \pm 0.07^{a, A}$ & $1.59 \pm 0.11^{a b, B}$ & $1.58 \pm 0.22^{a, B}$ & $1.96 \pm 0.24^{a b, B}$ & $2.86 \pm 0.75^{c, C}$ \\
\hline PAS & $1.34 \pm 0.34^{a, A}$ & $2.11 \pm 0.18^{b, B}$ & $3.09 \pm 0.13^{b, C}$ & $2.86 \pm 0.24^{b, C}$ & $2.42 \pm 0.22^{b c, B}$ \\
\hline GRA & $1.40 \pm 0.13^{a, A}$ & $3.73 \pm 0.31^{c, B}$ & $7.01 \pm 0.57^{c, C}$ & $6.76 \pm 0.64^{c, C}$ & $6.81 \pm 0.52^{d, C}$ \\
\hline KET & $1.58 \pm 0.19^{a, A}$ & $5.65 \pm 0.46^{d, B}$ & $8.48 \pm 0.33^{d, C}$ & $10.37 \pm 0.28^{d, D}$ & $10.61 \pm 0.35^{e, D}$ \\
\hline MUS & $22.92 \pm 1.51^{b, A}$ & $26.93 \pm 0.71^{f, B}$ & $27.21 \pm 0.27^{f, B}$ & $34.12 \pm 0.59^{\mathrm{b}, \mathrm{D}}$ & $30.48 \pm 0.72^{f, C}$ \\
\hline SOY & $1.70 \pm 0.22^{a, A}$ & $6.85 \pm 0.77^{\mathrm{a}, \mathrm{B}}$ & $11.15 \pm 0.98^{\mathrm{a}, \mathrm{C}}$ & $10.14 \pm 1.42^{\mathrm{d}, \mathrm{C}}$ & $9.78 \pm 0.75^{\mathrm{e}, \mathrm{C}}$ \\
\hline
\end{tabular}

Different letters show statistical difference $(p<0.05)$ between the products tested. Capital letters show statistical difference between the experimental times for each product. $\Delta E$ values considered unacceptable (perceived by the human eye). 
Table 3 - Means and standard deviations of $\Delta V$ values for each experimental time.

\begin{tabular}{c|c|c|c|c|c}
\hline Groups & T1 & T2 & T3 & T4 & T5 \\
\hline DRY & $-4.11 \pm 4.96^{\mathrm{a}, \mathrm{A}}$ & $-5.27 \pm 3.81^{\mathrm{a}, \mathrm{A}}$ & $-5.95 \pm 5.02^{\mathrm{a}, \mathrm{A}}$ & $0.66 \pm 5.26^{\mathrm{a}, \mathrm{B}}$ & $-2.81 \pm 3.21^{\mathrm{a}, \mathrm{A}}$ \\
\hline DW & $7.12 \pm 3.49^{\mathrm{bc}, \mathrm{A}}$ & $10.48 \pm 1.10^{\mathrm{b}, \mathrm{A}}$ & $16.90 \pm 3.09^{\mathrm{b}, \mathrm{B}}$ & $8.70 \pm 3.56^{\mathrm{ab}, \mathrm{B}}$ & $19.51 \pm 3.64^{\mathrm{bc}, \mathrm{B}}$ \\
\hline ORA & $1.53 \pm 1.87^{\mathrm{ab}, \mathrm{B}}$ & $-1.70 \pm 2.79^{\mathrm{a}, \mathrm{A}}$ & $1.93 \pm 1.47^{\mathrm{a}, \mathrm{B}}$ & $0.92 \pm 2.06^{\mathrm{a}, \mathrm{B}}$ & $0.66 \pm 1.48^{\mathrm{a}, \mathrm{AB}}$ \\
\hline PAS & $6.09 \pm 3.35^{\mathrm{bc}, \mathrm{A}}$ & $11.21 \pm 2.87^{\mathrm{b}, \mathrm{AB}}$ & $17.18 \pm 5.86^{\mathrm{b}, \mathrm{BC}}$ & $13.44 \pm 7.06^{\mathrm{b}, \mathrm{B}}$ & $21.15 \pm 5.76^{\mathrm{c}, \mathrm{C}}$ \\
\hline GRA & $5.30 \pm 2.82^{\mathrm{bc}, \mathrm{A}}$ & $11.12 \pm 2.76^{\mathrm{b}, \mathrm{AB}}$ & $13.87 \pm 3.56^{\mathrm{b}, \mathrm{B}}$ & $11.43 \pm 2.94^{\mathrm{b}, A B}$ & $15.26 \pm 6.97^{\mathrm{bc}, \mathrm{B}}$ \\
\hline KET & $5.78 \pm 1.74^{\mathrm{bc}, \mathrm{A}}$ & $6.34 \pm 1.96^{\mathrm{b}, \mathrm{A}}$ & $17.55 \pm 3.81^{\mathrm{b}, \mathrm{B}}$ & $13.85 \pm 4.42^{\mathrm{b}, \mathrm{B}}$ & $11.54 \pm 3.71^{\mathrm{b}, \mathrm{B}}$ \\
\hline MUS & $9.06 \pm 3.17^{\mathrm{c}, \mathrm{AB}}$ & $8.10 \pm 2.65^{\mathrm{b}, \mathrm{A}}$ & $17.18 \pm 5.86^{\mathrm{b}, \mathrm{D}}$ & $15.40 \pm 3.28^{\mathrm{b}, \mathrm{C}}$ & $13.35 \pm 2.45^{\mathrm{bc}, \mathrm{BC}}$ \\
\hline SOY & $6.01 \pm 3.06^{\mathrm{bc}, \mathrm{A}}$ & $9.26 \pm 3.50^{\mathrm{b}, \mathrm{AB}}$ & $17.63 \pm 5.04^{\mathrm{b}, \mathrm{C}}$ & $12.45 \pm 5.04^{\mathrm{b}, \mathrm{ABC}}$ & $13.96 \pm 4.45^{\mathrm{bc}, \mathrm{BC}}$ \\
\hline
\end{tabular}

Different letters show statistical difference $(p<0.05)$ between the products tested. Capital letters show statistical difference between the experimental times for each product.

DRY, PAS and ORA did not present color alterations perceptible to the observer $(\Delta E<3.3)$. DW group showed some change in the color $(\Delta E=3.41)$ after 14 days (T3); however, until the end of the experiment, it was able to recover its original color. The groups KET, GRA and SOY showed color alteration after 7 days (T2). The greatest color alteration occurred in the group MUS (T4 = 34.12), at all experimental times, and this alteration could be noted after only 24 hours.

\section{Microhardness change}

Means, standard deviations $( \pm)$ and statistical difference of microhardness change $(\Delta V)$ for the tested substances at each experimental time are presented in Table 3. After one day MUS group showed the greatest change in the microhardness $(\mathrm{T} 1=9.06)$. At the end of the experiment, PAS group showed the greatest microhardness alteration, followed by DW, GRA, SOY and MUS. KET and ORA groups were next in a decreasing sequence. The group DRY showed a significant microhardness change after 21 days; however, at the end of the experiment, its microhardness was not significantly different from the initial value.

\section{Correlation between color and microhardness alterations}

The results of the Pearson's correlation test are presented in Table 4. Groups DW, KET, GRA and SOY showed a significant positive correlation be-
Table 4 - Correlation between $\Delta E$ and $\Delta V$ values.

\begin{tabular}{c|c|c|c}
\hline Groups & $R$ (Pearson) & $P$ & Significant \\
\hline DRY & 0.145 & 0.488 & $\mathrm{~ns}$ \\
\hline ORA & -0.076 & 0.717 & $\mathrm{~ns}$ \\
\hline MUS & 0.295 & 0.153 & $\mathrm{~ns}$ \\
\hline KET & 0.602 & $0.001^{* *}$ & $\mathrm{sig}$ \\
\hline DW & 0.496 & $0.012^{*}$ & $\mathrm{sig}$ \\
\hline PAS & 0.384 & 0.058 & $\mathrm{~ns}$ \\
\hline SOY & 0.634 & $0.001^{* *}$ & $\mathrm{sig}$ \\
\hline GRA & 0.536 & $0.006^{* *}$ & $\mathrm{sig}$ \\
\hline
\end{tabular}

${ }^{* *}$ significant at $1 \% ;{ }^{*}$ significant at $5 \%$.

tween $\Delta E$ and $\Delta V$ values.

\section{Discussion}

It is widely accepted that the susceptibility to extrinsic staining as well as the degradation of a composite can be determinate by its degree of water sorption. According to Bagheri et al., ${ }^{5}$ if the composite is able to absorb water, then it is also capable of absorbing other fluids, resulting in its discoloration $^{17}$ and in the reduction of its mechanical properties due to polymer matrix degradation. ${ }^{18}$ Fluid absorption occurs mainly as direct absorption in the resin matrix. The glass filler particles will not absorb water into the bulk of the material, but can adsorb water onto the surface. Extra water sorption may decrease the life of resin composites by expanding and plasticizing the resin component, hydrolyz- 
ing the silane and causing microcrack formation. Therefore, the microcracks or the interfacial gaps at the interface between filler and matrix allow stain penetration and discoloration. ${ }^{5}$ This theory could be confirmed in this study, as can be observed in the alterations found in DW group for both variables: $\Delta E$ and $\Delta V$.

The ability of the composite to absorb fluids is strongly related to the nature of the material. It was observed that hydrophobic materials, with the absence of a hydroxyl group in their composition, showed low water sorption, but were stained by hydrophobic solutions, whereas hydrophilic materials with a high degree of water sorption were stained by hydrophilic substances in aqueous solutions. ${ }^{5}$

According to the manufacturer, the material Filtek Z-250 used in this study is a universal microhybrid composite resin with an organic matrix of Bis-GMA, UDMA and Bis-Hema. Its filler consists of $60 \%$ by volume of zircon/silica particles ranging from $0.01-3.5 \mu \mathrm{m}$. The presence of UDMA and, more importantly, Bis-Hema, makes this composite more color stable and more hydrophobic. ${ }^{19,20}$ This more hydrophobic characteristic could explain the fact that, in this study, mustard was the substance that promoted the greatest staining. This condiment is composed of vinegar, mustard, corn, sugar, salt, food flavoring, conservative and curcuma, which is a rhizome extensively used in industry to obtain food coloring and pharmaceutical products. ${ }^{21}$ Curcuma has a brilliant yellow color and is insoluble in water, i.e. hydrophobic. This great capacity of curcuma to stain composites was also previously observed by Stober et al. ${ }^{22}$

The other substances that also had an impact on the composite color were ketchup, grape juice and soy sauce. Ketchup, another condiment, is very popular among populations all over the world, and its red color is attributed to a substance called lycopene which, like curcuma, is also insoluble in water. ${ }^{2}$

The color of grapes comes from the anthocynanins, which are water-soluble vacuolar pigments ${ }^{23}$ that may appear red, purple, or blue, according to the $\mathrm{pH}$. Differently from the pigments found in mustard and in ketchup, anthocyanins are hydrophilic, and so is the caramel coloring, the pigment present in the soy sauce. In these circumstances, one might suppose that the staining caused by these two pigments was due to their adsorption on the composite surface. However, we do not believe that this was the case, since in order to prevent the mechanical retention of these pigments on the composite surface, all specimens were washed and brushed before each evaluation. It can be speculated that some absorption by the hydrophilic component of the organic matrix, mainly the Bis-GMA, ${ }^{4,24}$ might have occurred.

Immersion of the specimens in deionized water did not alter the color of the composite to a considerable extent, which is in agreement with other investigations. ${ }^{13,22,25}$ Although a perceptible color alteration could be noticed after 7 days in this group, by the end of the experiment, the specimens were able to return to their original color. As deionized water has no pigments, this reported small color alteration might be attributed to some water sorption of the organic matrix. On the other hand, the specimens kept in the dry condition did not present any color alteration over the course of time.

As regards microhardness alterations, it was observed that acid substances can cause a reduction in the surface microhardness of composites by softening the bis phenol-A-glycidyl methacrylate-based polymers present in the organic matrix. ${ }^{10,14,26}$ In agreement with this theory, Villalta et al..$^{25}$ stated that low $\mathrm{pH}$ may indeed affect the surface integrity of composite resins, and for this reason, it could also promote an increase in the susceptibility to staining.

As can be observed in Table 1, all the solutions tested in this study have low $\mathrm{pH}$ and, therefore, a high potential to affect the superficial integrity of the composite. Fontes et al. ${ }^{10}$ believe that the low $\mathrm{pH}$ of the grape juice affected the resin surface, increasing pigment absorption. According to this study, the substance that promoted the greatest microhardness change was passion fruit juice, which has a $\mathrm{pH}=3.13$. However, it was not clear why orange juice with a $\mathrm{pH}=3.01$ did not promote a microhardness alteration comparable with that of passion fruit or even grape juice ( $\mathrm{pH}=2.98)$; or why deionized water, with a $\mathrm{pH}$ value of 6.3 , caused the second greatest microhardness change. In these groups, 
microhardness alterations could not be exclusively associated with the $\mathrm{pH}$. Thus, to elucidate these results, further investigations must be conducted, involving the study of other chemical and physical characteristics of these substances that might have exerted some influence on the change in microhardness of the composite.

It was only possible to determine a positive significant correlation between the two variables tested in this study in the groups treated with deionized water, grape juice, ketchup and soy sauce, which means that discoloration of the composite cannot always be associated with its surface degradation. Yanikoğlu et al. ${ }^{27}$ also concluded that the values of composite materials were statistically different in different immersion solutions.

According Mundim et al. ${ }^{28}$ patients routinely ask dentists how long an esthetic restoration should last, and whether their eating habits may influence the quality and longevity of the restoration. Knowledge

\section{References}

1. Ardu S, Braut V, Gutemberg D, Krejci I, Dietschi D, Feilzer AJ. A long-term laboratory test on staining susceptibility of esthetic composite resin materials. Quintessence Int. 2010 Sep;41(8):695-702.

2. Buchalla W, Attin T, Hilgers RD, Hellwig E. The effect of water storage and light exposure on the color and translucency of a hybrid and a microfilled composite. J Prosthet Dent. 2002 Mar;87(3):264-70.

3. Braga SRM, Vasconcelos BT, Macedo MRP, Martins VRG, Sobral MAP. Reasons for placement and replacement of direct restorative materials in Brazil. Quintessence Int. 2007 Apr;38(4):e.189-94.

4. Topcu FT, Sahinkesen G, Yamanel K, Erdemir U, Oktay EA, Ersahan S. Influence of different drinks on the colour stability of dental resin composites. Eur J Dent. 2009 Jan;3(1):50-6.

5. Bagheri R, Burrow MF, Tyas M. Influence of food-simulating solutions and surface finish on susceptibility to staining of aesthetic restorative materials. J Dent Res. 2005 May;33(5):38998.

6. Douglas WM, Craig RG. Resistance to extrinsic stains by hydrophobic composite resin systems. J Dent Res. 1982 Jan;61(1):41-3.

7. Reis AF, Giannini M, Lovadino JR, Ambrosano GM. Effects of various finishing systems on the surface roughness and staining susceptibility of packable composite resins. Dent Mater. 2003 Jan;19(1):12-8. of the effects of staining potential on the surface of a composite resin could guide clinicians as regards the instructions ${ }^{1}$ they give their patients after the operatory procedure, to assure better color stability and long-term maintenance of the restoration.

\section{Conclusions}

Considering the limitations of this study, it was possible to conclude that:

1. Mustard was the substance that promoted the greatest color alteration.

2. Passion fruit juice caused the greatest microhardness change.

3. Not all color alteration could be associated with surface degradation.

\section{Acknowledgements}

The authors would like to thank the FAPESP and CAPES for their financial support.
8. Gross MD, Moser JB. A colorimetric study of coffee and tea staining of four composite resins. J Oral Rehabil. 1977 Oct;4(4):311-22.

9. Yazici AR, Celik C, Dayangaç B, Ozgünaltay G. The effect of curing units and staining solutions on the color stability of resin composites. Oper Dent. 2007 Nov-Dec;32(6):616-22.

10. Fontes ST, Fernández MR, Moura CM, Meireles SS. Color stability of a nanofill composite: effect of different immersion media. J Appl Oral Sci. 2009 Sep-Oct;17(5):388-91.

11. Güler AU, Güler E, Yücel AC, Ertaş E. Effects of polishing procedures on color stability of composite resins. J Appl Oral Sci. 2009 Mar-Apr;17(2):108-12.

12. Curtin JA, Lu H, Milledge TJ, Hong L, Peterson J. In vitro staining of resin composites by liquids ingested by children. Pediatric Dent. 2008 Jul-Aug;30(4):317-22.

13. Catelan A, Briso AL, Sundfeld RH, Goiato MC, Dos Santos $\mathrm{PH}$.Color stability of sealed composite resin restorative materials after ultraviolet artificial aging and immersion in staining solutions.J Prosthet Dent. 2011 Apr;105(4):236-41.

14. Honório HM, Rios D, Francisconi LF, Magalhães AC, Machado MA, Buzalaf MA. Effect of prolonged erosive $\mathrm{pH}$ cycling on different restorative materials. J Oral Rehabil. 2008 Dec;35(12):947-53.

15. Okte Z, Villalta P, García-Godoy F, Lu H, Powers JM. Surface hardness of resin composites after staining and bleaching. Oper Dent. 2006 Sep-Oct;31(5):623-8. 
16. Ruyter IE, Nilner K, Moiler B. Color stability of dental composite resin materials for crown and bridge veneers. Dent Mater. 1987 Oct;3(5):246-51.

17. Galvão AP, Jacques LB, Dantas L, Mathias P, Mallmann A.Effect of lipstick on composite resin color at different application times. J Appl Oral Sci. 2010 Dec;18(6):566-71.

18. Ferracane JL. Hygroscopic and hydrolytic effects in dental polymer networks. Dent Mater. 2006 Mar;22(3):211-22.

19. Kerby RE, Knobloch LA, Schricker S, Gregg B. Synthesis and evaluation of modified urethane dimethacrylate resins with reduced water sorption and solubility. Dent Mater. 2009 Mar;25(3):302-13.

20. Siderdou I, Tserki V, Papanastasiou G. Study of water sorption, solubility and modulus of elasticity of light cured dimethacrylate resins. Biomaterials. 2003 Feb;24(4):655-65.

21. Goel A, Kunnumakkara AB, Aggarwal BB. Curcumin as " $\mathrm{Cu}-$ recumin": from kitchen to clinic. Biochem Pharmacol. 2008 Feb;75(4):787-809.

22. Stober T, Gilde H, Lenz P. Color stability of highly filled composite resin materials for facings. Dent Mater. 2001 Jan;17(1):87-94.
23. Passamonti S, Vrhovsek U, Vanzo A, Mattivi F. Fast access of some grape pigments to the brain. J Agric Food Chem. 2005 Sep 7;53(18):7029-34.

24. Shobha HK, Sankarapandian M, Kalachandra S, Taylor DF, McGrath JE. Structure property relationship among novel dental composite matrix resins. J Mater Sci Mater Med. 1997 Jun;8(6):385-9.

25. Villalta P, Lu H, Okte Z, Garcia-Godoy F, Powers JM. Effects of staining and bleaching on color change of dental composite resins. J Prosthet Dent. 2006 Feb; 95(2):137-42.

26. Canay S, Cehreli MC. The effect of current bleaching agents on the color of light-polymerized composite in vitro. J Prosthet Dent. 2003 May;89(5):474-8.

27. Yanikoğlu N, Duymuş ZYeşil, Yilmaz B. Effects of different solutions on the surface hardness of composite resin Materials. Dent Mater J. 2009 May;28(3):344-51.

28. Mundim FM, Garcia LFR, Pires-de-Souza FCP. Effect of staining solutions and repolishing on color stability of direct composites. J Appl Oral Sci. 2010 Jun;18(3):249-54. 